\title{
FITORREMEDIAÇÃO DE SOLOS CONTAMINADOS COM CHUMBO UTILIZANDO Jatropha curcas $L$.
}

\author{
A de F. GOUVEIA ${ }^{1}$, P.D. MACRUZ ${ }^{2}$ e J.H.B. de ARAÚJO ${ }^{3}$ \\ ${ }^{1}$ Universidade Tecnológica Federal do Paraná, Departamento de Engenharia Ambiental \\ ${ }^{2}$ Universidade Tecnológica Federal do Paraná, Departamento de Engenharia Ambiental \\ ${ }^{3}$ Universidade Tecnológica Federal do Paraná, Departamento de Engenharia Ambiental \\ E-mail para contato: gouveiaf.andreia@gmail.com
}

\begin{abstract}
RESUMO - A fitorremediação é conhecida como uma técnica que utiliza sistemas vegetais como agentes para recuperar o ambiente. A espécie Jatropha curcas L. mais conhecida como pinhão manso e com alto potencial para recuperar áreas degradadas foi utilizada no trabalho para se verificar o seu potencial de fitoextração. As amostras foram contaminadas com sal de chumbo $\left(\mathrm{Pb}\left(\mathrm{NO}_{3}\right)_{2}\right) \mathrm{em}$ diferentes concentrações $(160 \mathrm{mg}, 800 \mathrm{mg}$ e $1600 \mathrm{mg}$, equivalente a $100 \mathrm{mg}, 500$ $\mathrm{mg}$ e $1000 \mathrm{mg}$ de chumbo por quilo de solo utilizado respectivamente). Após 70 dias, as plantas foram quantificadas em seu desenvolvimento quanto à altura, peso e diâmetro, e depois encaminhadas ao Laboratório Santa Rita, na cidade de Mamborê, Paraná para a determinação do teor de chumbo adsorvido. Os resultados obtidos na fitoextração das amostras foram de 2,40 mg absorvidos para a amostra com $100 \mathrm{mg}$ de solo contaminado, 21,06 mg absorvidos para a amostra com $500 \mathrm{mg}$ e 71,46 mg de chumbo adsorvido para a amostra com $1000 \mathrm{mg}$.
\end{abstract}

\section{INTRODUÇÃO}

O chumbo, considerado um metal pesado, está amplamente distribuído no planeta, incluindo sua emissão de fontes naturais como vulcões, intemperismo geoquímico e emissões provenientes do mar e emissão de fontes antrópicas, como indústrias. Os metais pesados não se degradam após serem emitidos, permanecem no ambiente durante centenas de anos, afetando a vegetação, correntes de água, animais e os seres humanos.

Dentre os principais efeitos causados pelo excesso deste metal às plantas tem-se a redução do crescimento, clorose, inibição da fotossíntese, alteração da nutrição mineral, do estado hídrico e do balanço hormonal. Além disso, o chumbo pode afetar a estrutura e a permeabilidade das membranas acarretando em diversos efeitos morfológicos, fisiológicos e bioquímicos (SHARMA et al., 2005).

Uma das alternativas para a despoluição ambiental é a fitorremediação, técnica que emprega sistemas vegetais fotossintetizantes e sua microbiota como agentes remediadores.

O estudo da fitorremediação tomou impulso nos últimos dez anos, quando se verificou que a zona radicular das plantas apresenta a capacidade de biotransformar moléculas orgânicas exógenas (externas). A rizosfera, como é denominada esta zona, tem sido desde 
então estudada por sua importante função: fonte de nutrientes para os diversos microrganismos que co-habitam nesta região. Assim, como a sua capacidade de estimular a degradação de pesticidas, hidrocarbonetos aromáticos polinucleares e outras substâncias químicas (FAÇANHA et al, 2007).

O pinhão-manso (Jatropha curcas L.), da família das Euphorbiaceae, tem sido citado na literatura como uma cultura rústica, que sobrevive bem em condições de solos marginais de baixa fertilidade natural se adaptando às mais diversas condições edafoclimáticas (ARRUDA et al., 2004).

Além das suas sementes produzirem óleo utilizado para envernizar móveis e produção de biodiesel, esta espécie tem sido usada como cerca viva e vem sendo plantada com sucesso, visando o controle da erosão e a contenção de encostas e dunas, sendo apontada como uma planta capaz de recuperar áreas degradadas (SATURNINO et al., 2005).

O presente trabalho teve como principal objetivo analisar a planta da espécie pinhão manso como remediadora para solos contaminados com nitrato de chumbo.

\section{PROCEDIMENTO EXPERIMENTAL}

O material vegetal testado como fitorremediador foi o pinhão-manso (Jatropha curcas L.), cujas sementes foram coletadas na Avenida Jorge Walter, próximo ao supermercado Paraná, em Campo Mourão, sendo identificada pelo professor Dr. Marcelo Galeazzi Caxambu, responsável pelo Herbário da Universidade Tecnológica Federal do Paraná, campus Campo Mourão, com número de voucher 1975.

Para desenvolvimento do experimento foram determinadas as concentrações de chumbo necessárias a serem misturadas ao solo. Devido à disponibilidade e as condições de insolubilidade do chumbo, utilizou-se na realização do experimento, Nitrato de Chumbo $\mathrm{Pb}\left(\mathrm{NO}_{3}\right)_{2}$, cedido pela Universidade Tecnológica Federal do Paraná câmpus Campo Mourão. A quantidade do sal necessária para atingir a concentração por quilo de solo foi determinado por relações estequiométricas. Utilizando os resultados dos cálculos, realizou-se a pesagem do Nitrato de Chumbo com ajuda de balança analítica de precisão Celtac FA 2014N, as massas pesadas foram de: $0,16 \mathrm{~g} ; 0,8 \mathrm{~g} ; 1,6 \mathrm{~g}$, misturadas a $1 \mathrm{~kg}$ de extrato de solo.

As quantidades calculadas foram colocadas em recipientes plásticos de polipropileno (vasos) devidamente identificados. No tratamento Testemunha (controle) foi utilizado solo sem nenhum tipo de adição de contaminantes. $\mathrm{O}$ experimento foi realizado em triplicata para as três diferentes concentrações e testemunha, totalizando 12 sementes: 3 sementes em $1 \mathrm{~kg}$ solo $+0,16$ g $\mathrm{Pb}\left(\mathrm{NO}_{3}\right)_{2} ; 3$ sementes em $1 \mathrm{~kg}$ solo $+0,8 \mathrm{~g} \mathrm{~Pb}\left(\mathrm{NO}_{3}\right)_{2} ; 3$ sementes em $1 \mathrm{~kg}$ solo $+1,6 \mathrm{~g} \mathrm{~Pb}\left(\mathrm{NO}_{3}\right)_{2} ; 3$ sementes na testemunha.

O extrato de solo utilizado no experimento foi da marca Terra Vegetal, possuindo em sua composição turfa, vermicomposto, casca de Pinus, casca de arroz carbonizado, oriundo da cidade de Toledo/PR. 
As sementes foram plantadas no mês de novembro de 2013, época favorável à germinação das sementes. O mecanismo de fitorremediação utilizado foi o de fitoextração que consiste na absorção do poluente contido no meio, em que ocorre o armazenamento no tecido vegetal, facilitando o descarte do material.

Após 70 dias do plantio, as amostras das plantas de todas as concentrações, inclusive testemunha, foram encaminhadas para o laboratório de análises Santa Rita, localizado na cidade de Mamborê, Paraná. Antes de serem enviadas para análise, as amostras foram retiradas do solo e lavadas para total remoção de sólidos e sujeiras. Também foram efetuadas as medidas de raiz, diâmetro do caule, tamanho da planta com a raiz, tamanho das folhas maior, média e menor e feita a contagem do número de plantas que nasceram e do número de folhas para cada concentração. No laboratório a metodologia para análise do tecido vegetal foi a Extração via úmida utilizando ácido nítrico e perclórico, e a determinação dos metais por Espectrofotometria de Absorção Atômica.

\section{RESULTADO E DISCUSSÃO}

Para cada concentração de chumbo, foram quantificadas as plantas que germinaram e suas características físicas. A medida dessas características é mostrada no gráfico da Figura 1 e na Tabela 1:

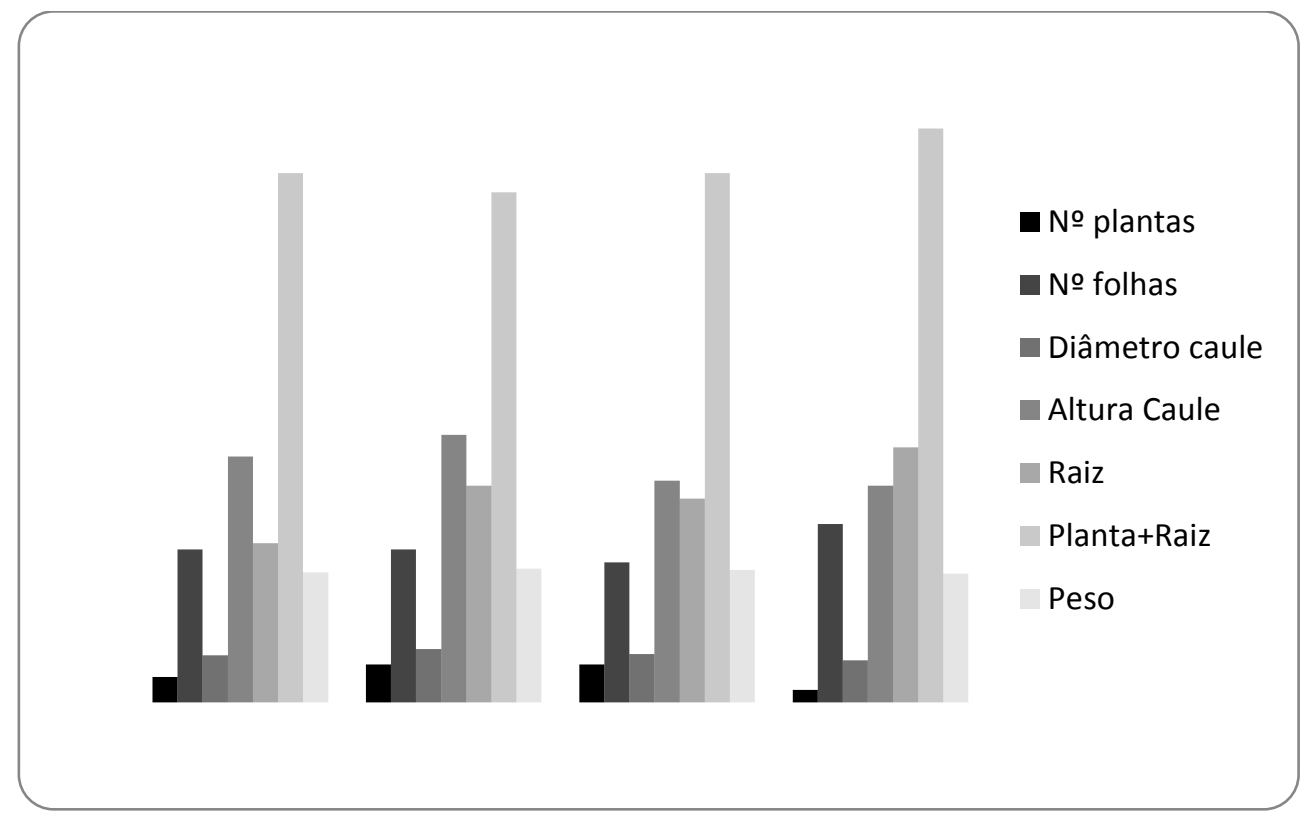

Figura 1: Características morfológicas das amostras de pinhão manso contaminadas com chumbo. 
Tabela1. Relação das medidas das folhas das amostras após 70 dias.

\begin{tabular}{|c|c|c|c|c|c|c|}
\hline \multirow[t]{2}{*}{$\begin{array}{l}\text { Concentrações de } \\
\text { nitrato de chumbo }\end{array}$} & \multicolumn{2}{|c|}{$\begin{array}{l}\text { Tamanho da folha } \\
\text { maior }\end{array}$} & \multicolumn{2}{|c|}{$\begin{array}{c}\text { Tamanho da folha } \\
\text { média }\end{array}$} & \multicolumn{2}{|c|}{$\begin{array}{c}\text { Tamanho da folha } \\
\text { menor }\end{array}$} \\
\hline & Largura & Comp. & Largura & Comp. & Largura & Comp. \\
\hline Testemunha $0,0 \mathrm{~g}$ & $9,3 \mathrm{~cm}$ & $8,3 \mathrm{~cm}$ & $7,8 \mathrm{~cm}$ & $7,3 \mathrm{~cm}$ & $1,1 \mathrm{~cm}$ & $1,7 \mathrm{~cm}$ \\
\hline Concentração $0,16 \mathrm{~g}$ & $8,4 \mathrm{~cm}$ & $8,7 \mathrm{~cm}$ & $6,5 \mathrm{~cm}$ & $7 \mathrm{~cm}$ & $1,8 \mathrm{~cm}$ & $2,2 \mathrm{~cm}$ \\
\hline Concentração $0,8 \mathrm{~g}$ & $8,9 \mathrm{~cm}$ & $9 \mathrm{~cm}$ & $5 \mathrm{~cm}$ & $6 \mathrm{~cm}$ & $1,5 \mathrm{~cm}$ & $2,5 \mathrm{~cm}$ \\
\hline Concentração 1,6 g & $11,2 \mathrm{~cm}$ & $10,7 \mathrm{~cm}$ & $8,4 \mathrm{~cm}$ & $7,5 \mathrm{~cm}$ & $3 \mathrm{~cm}$ & $3 \mathrm{~cm}$ \\
\hline
\end{tabular}

Analisando os resultados das medidas, observa-se que apesar da contaminação do solo com o nitrato de chumbo, as plantas não apresentaram grande influência negativa durante o crescimento por 70 dias, visto que seus tamanhos são muito parecidos com o da testemunha.

Também pode ser analisado vendo as fotografias na Figura 2:

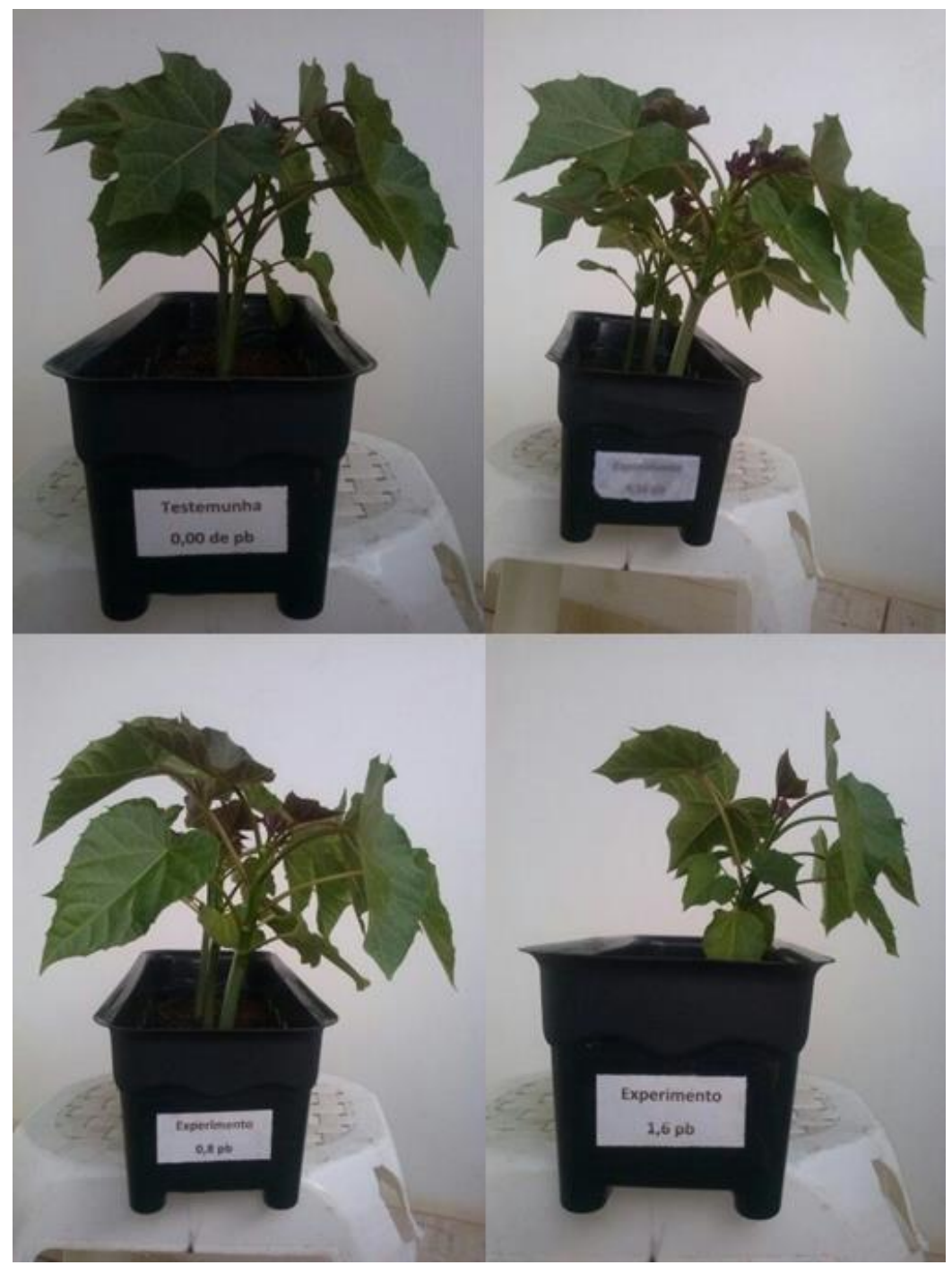

Figura 2- Fotografias das amostras de Pinhão manso. Em cima: planta da esquerda com concentração $0,0 \mathrm{~g}$ de $\mathrm{Pb}\left(\mathrm{NO}_{3}\right)_{2}$; planta da direita com $0,16 \mathrm{~Pb}\left(\mathrm{NO}_{3}\right)_{2}$. Em baixo: planta da esquerda com concentração $0,8 \mathrm{~g}$ de $\mathrm{Pb}\left(\mathrm{NO}_{3}\right)_{2}$; planta da direita com concentração de 1,6 de $\mathrm{Pb}\left(\mathrm{NO}_{3}\right)_{2}$. 
Após 70 dias, efetuou-se a retirada das amostras do solo, onde foram embaladas em sacos plásticos (Figura 3) e enviadas para o laboratório. O resultado da análise laboratorial das amostras de pinhão manso no solo contaminado com chumbo é apresentado na Tabela 2, e na Figura 4 é apresentado um gráfico para melhor visualização.

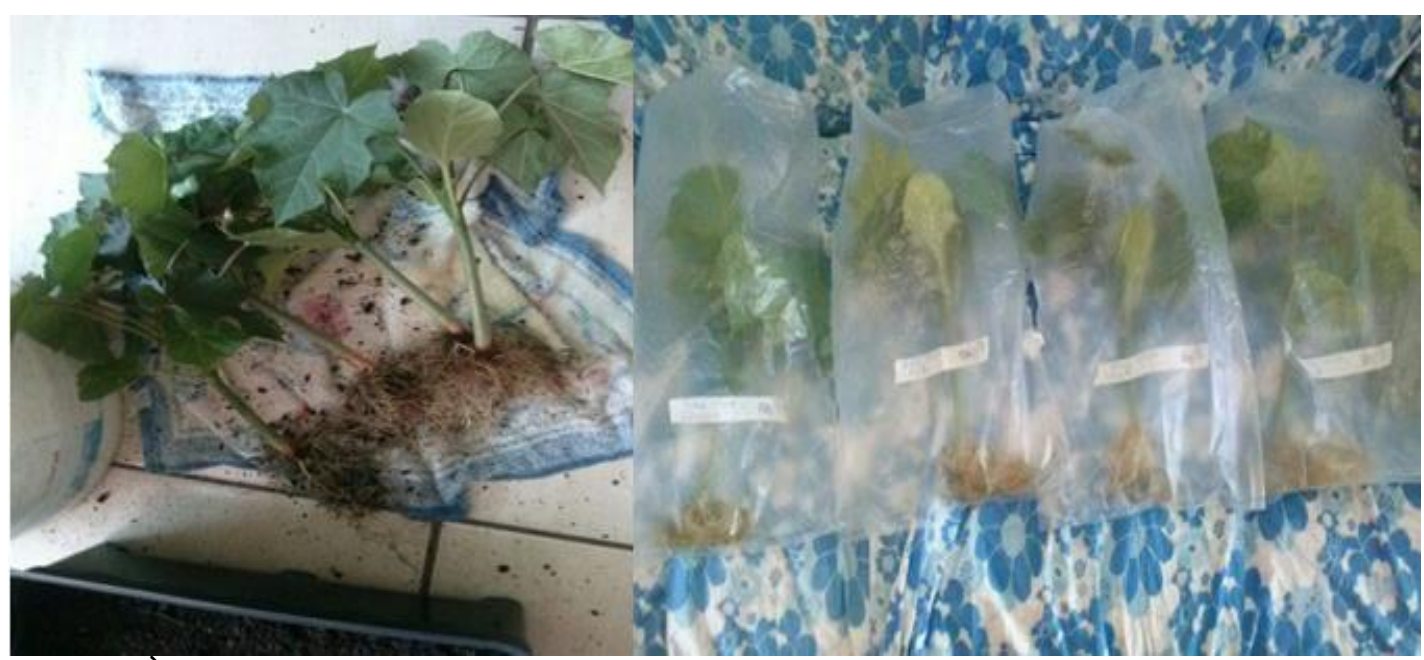

Figura 3 - Â esquerda amostras retiradas do solo e com raiz lavada; à direita amostras embaladas e prontas para serem enviadas para o laboratório.

Tabela 2. Resultados da Análise laboratorial da fitoextração do Pinhão Manso.

\begin{tabular}{|c|c|c|c|c|}
\hline Concentração de $\mathrm{Pb}\left(\mathrm{NO}_{3}\right)_{2}$ & Testemunha & $\mathrm{PM} 1$ & $\mathrm{PM} 2$ & $\mathrm{PM} 3$ \\
\hline Concentração no solo & $0,0 \mathrm{mg}$ & $160 \mathrm{mg}$ & $800 \mathrm{mg}$ & $1600 \mathrm{mg}$ \\
\hline Fitoextração do Pinhão Manso & $<0,06 \mathrm{mg}$ & $2,40 \mathrm{mg}$ & $21,06 \mathrm{mg}$ & $71,46 \mathrm{mg}$ \\
\hline
\end{tabular}

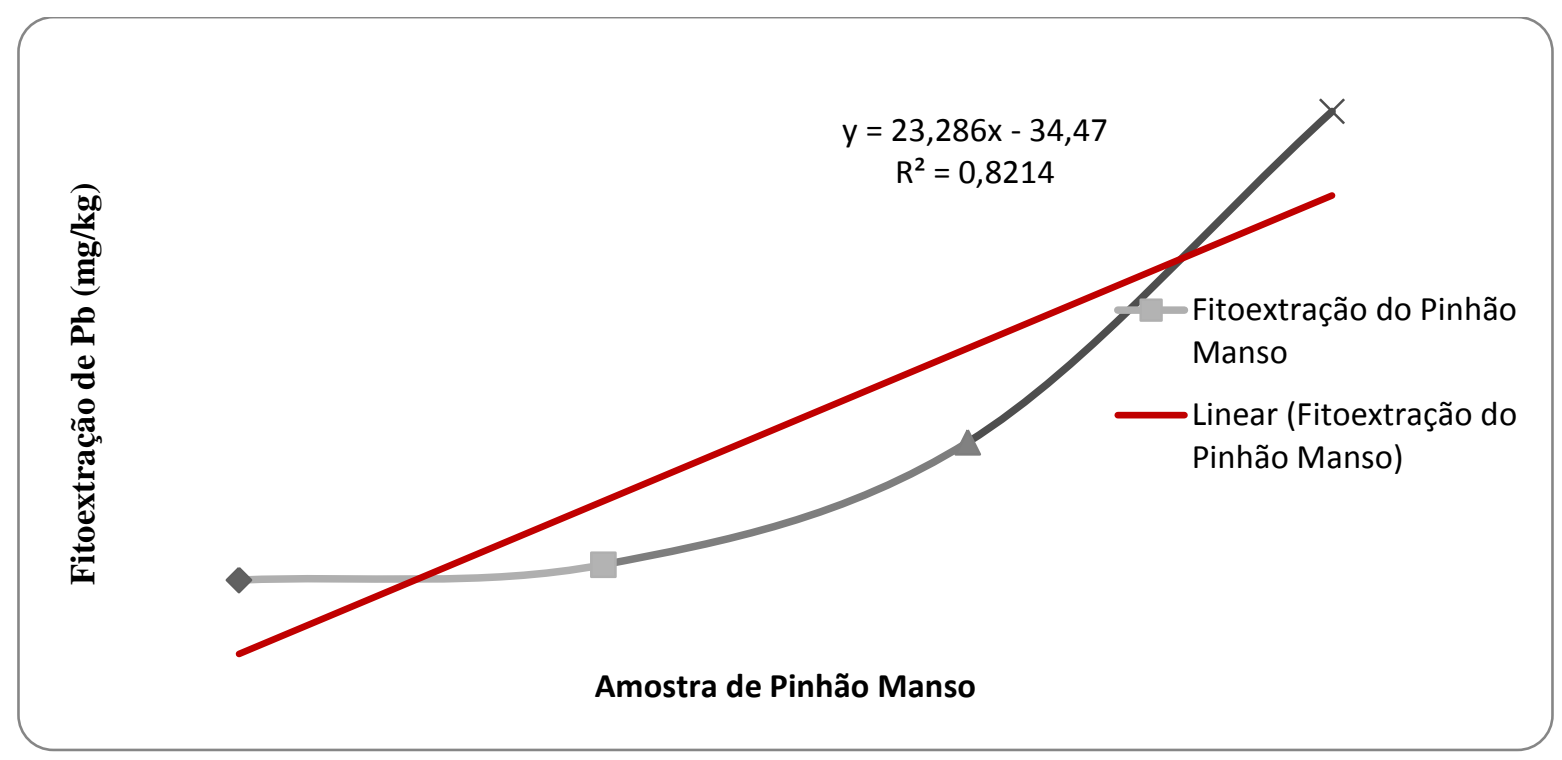

Figura 4 - Gráfico com os resultados referentes a fitoextração do pinhão manso em diferentes concentrações de chumbo no solo. 
Analisando os resultados, pode-se observar que para cada $160 \mathrm{mg}$ de nitrato de chumbo aplicado no solo para o pinhão manso 1 , foram absorvidos 2,40 mg do mesmo. Para o pinhão manso 2, de $800 \mathrm{mg}$ de nitrato de chumbo aplicado no solo, foram absorvidos 21,06 mg. E finalmente para o pinhão manso 3, de $1600 \mathrm{mg}$ de nitrato de chumbo aplicado no solo, foram absorvidos 71,46 mg.

A planta Testemunha que teve $0,0 \mathrm{mg}$ de nitrato de chumbo aplicado ao solo, apresentou uma absorção no solo menor que $0,06 \mathrm{mg}$. No experimento utilizou-se extrato de solo, a fim de não ocorrer maiores alterações decorrentes da presença de metais pesados no solo, no entanto não é possível afirmar a total ausência de algum outro contaminante além do Nitrato de Chumbo utilizado no experimento.

\section{CONCLUSÃO}

Com base nos dados obtidos em laboratório é possível observar a eficiente fitoextração de chumbo realizada pela espécie Jatropha curcas $L$. Visivelmente todas as plantas apresentaram aspectos físicos semelhantes à planta testemunha $\left(0,0 \mathrm{~g} \mathrm{~Pb}\left(\mathrm{NO}_{3}\right)_{2}\right)$, sem nenhuma alteração física no crescimento das folhas e/ou caule e variação de cor ou manchas durante o crescimento. $\mathrm{O}$ bom desenvolvimento das plantas pode ter ocorrido pelas condições favoráveis de iluminação solar diárias, combinadas ao nível adequado de água. A espécie se adapta muito bem a diferentes condições climáticas, no entanto o clima mais seco e quente favorece seu crescimento segundo Arruda et al. (2004). Não é descartada a possibilidade que com o maior tempo de exposição da planta ao solo, esta viesse a apresentar diferentes características físicas além, claro de possivelmente o recipiente de polipropileno em que as sementes germinaram ser insuficiente para o crescimento das raízes e também favorecer as mudanças das características das plantas. $O$ fato de algumas sementes (3 no total) não germinar pode ter sido ocasionada pela viabilidade e qualidade da semente. As plantas no período de experimento de 70 dias apresentaram significativo desenvolvimento, não apresentando visíveis alterações causadas pelo Chumbo.

Devido aos resultados obtidos pode-se analisar que o pinhão manso pode ser utilizado na fitorremediação para os solos contaminados com as quantidades de chumbo apresentadas nesse trabalho. Importante continuar estudos sobre o potencial fitorremediador do pinhão manso com outras concentrações de chumbo e de outros metais pesados como níquel, cromo, mercúrio, etc., além de um período maior de crescimento da planta.

\section{REFERÊNCIAS}

ARRUDA, F. P. et al. Cultivo de pinhão-manso (Jatropha curcas L.) como alternativa para o semi-árido nordestino. Revista Brasileira de Oleaginosas e Fibrosas, v. 08, n. 01, p.789-799, 2004.

FAÇANHA, G.S.; CASTRO, R.F.; SANTANA, G.P.; Fitoextração de Pb2+ em latossolo contaminado por pb2+, cr2+ e zn2+ utilizando as espécies Cyperus surinamensis e Panicum maximum. Associação Brasileira de Química. Disponível em: <http://www.abq.org.br/cbq/2007/trabalhos/13/13-735-701.htm>, 2007. Acesso em: 5 jan 2014 
SATURNINO, H. M. et al. Cultura do pinhão-manso (Jatropha curcas L.). Informações Agropecuárias, v. 26, p. 44-78, 2005.

SHARMA, P.; DUBEY, R.S. Lead toxicity in plants. Brazilian Journal of Plant Physiology. Disponível em: $<$ http://www.scielo.br/scielo.php?pid=S167704202005000100004\&script=sci_arttext>,2005. Acesso em: 5 jan 2014. 